\title{
Drivers of wealth inequality in euro area countries: the effect of inheritance and gifts on household gross and net wealth distribution analysed by applying the Shapley value approach to decomposition*
}

\author{
Sebastian Leitner** \\ The Vienna Institute for International Economic Studies (wiiw), Vienna, Austria
}

This paper investigates the sources of inequality in household gross and net wealth across eight euro area countries applying the Shapley value approach to decomposition. The research draws on micro data from the Eurosystem Household Finance and Consumption Survey 2010. Dispersion in bequests and inter vivos transfers obtained by households are found to have a remarkable effect on wealth inequality that is stronger than that of income differences. In Austria, Germany and Cyprus the contribution of real and financial assets inherited or received as gifts to gross and net wealth inequality attains about 40 per cent. Nevertheless, the distribution of household characteristics (age, education, size, number of adults and children in the household, marital status) within countries also shapes the observed wealth dispersion.

Keywords: inequality, wealth distribution, decomposition analysis, inheritance, inter vivos transfers, income distribution, Europe

JEL codes: $D 31, D 63,052,057$

\section{INTRODUCTION}

The topic of household wealth holdings and their distribution has been discussed intensively in recent literature. One of the reasons for this is the increase of accumulated private wealth in relation to the national income in the affluent industrialised economies, particularly from the late 1970s onwards. Previously, during the first half of the twentieth century, two world wars and the economic depression between them effected a remarkable destruction of capital and thus a slump in the ratio of wealth to national income, which still remained relatively stable in the three decades following World War II (Piketty 2014). In addition to this development, in most OECD countries inequality of income rose

* Research was co-financed by the Austrian Chamber of Labour.

** Correspondence: The Vienna Institute for International Economic Studies (wiiw), Rahlgasse 3, 1060 Vienna, Austria; email: leitner@wiiw.ac.at. The author wishes to thank Stefan Jestl, Mario Holzner and Robert Stehrer (wiiw), Miriam Rehm and Matthias Schnetzer (AK-Wien), Philipp Korom (MPIfG - Cologne) and many others for helpful comments and assistance.

Received 08 June 2015, accepted 12 January 2016 
from the 1980s onwards (see for example OECD 2011). From research based on national (survey) data we can also conclude that, in at least a couple of the countries analysed, inequality of private wealth started to increase from the mid 1980s. For the United States this is detected by, for example, Kennickell (2003) and Wolff (2007; 2010); for Canada by Morissette et al. (2003); for Sweden by Klevmarken (2004); for Finland by Jäntii (2006); for Italy by Brandolini et al. (2004); for Germany by Hauser/Stein (2003); and for France by Piketty (2014). Overviews on developments in wealth inequality on the national level can also be found in Jäntti/Sierminska (2007) and Bonesmo Fredriksen (2012).

Another reason for the increased interest in research on household wealth is that micro data have recently become available that allow us to study wealth holdings and inequality, not only at the level of individual countries but also to compare the situation across countries, first via the Luxembourg Wealth Study Database and more recently based on data from the Eurosystem Household Finance and Consumption Survey (HFCS).

The present paper aims to analyse the sources of wealth inequality at the national level for various euro area countries and to compare those sources. My assumption is that the accumulation of wealth stocks by households is facilitated by the receipt of bequests or gifts (mostly of ancestors). Thus the wealth inequality of one generation can be passed on to the following, which over longer periods of time may result in an increase in the inequality of wealth within a society. As is laid down by Piketty/Zucman (2014), in Germany and France the ratio of bequests and gifts to the total stock of wealth has increased considerably, while remaining rather stable in the United Kingdom and Sweden.

In principle, households build up wealth stocks in three ways. Either they save out of their income from employment or self-employment or out of financial sources. The second way, important for many households, is to receive bequests or gifts and to save them instead of using the assets for consumptive purposes. A third form, which however cannot be dealt with in this paper, is that the assets owned appreciate in real terms. In my paper I am interested in the process of households' building-up of wealth stocks via the first two processes and the respective inequality in asset holdings that results therefrom. In order to detect the sources of wealth inequality across countries I apply a decomposition methodology based on the Shapley value approach to the inequality measure used most frequently in the literature: the Gini index. This decomposition method allows for an assessment of the relative importance of explanatory factors in inequality. While some authors (see the literature review below) have already worked for some decades on measuring how much of the accumulated stock of household wealth can be attributed to inheritance and intergenerational inter vivos transfers (contrary to wealth built up over the life cycle via saving and investment), decomposition approaches to the distribution of wealth have been performed only recently. However, in the literature one can so far find only decompositions by wealth source but not by subgroups. This latter analysis is performed in the following and should highlight the relative importance of inheritance, income and household characteristics in shaping wealth inequality in a cross-country manner, thus providing a novel contribution to the literature.

The paper is organised as follows: Section 2 provides a brief discussion of the literature on developments of household wealth inequality, the effects of inheritance and inter vivos transfers and on decomposition methods used to analyse income and wealth inequality. Section 3 discusses the most relevant aspects of the data used (sources, measurement issues and definitions) and Section 4 introduces the concept of the Shapley value approach to decomposition, discussing the way I apply this method. Section 5 presents the empirical results of the analysis for inequality in gross and net wealth stocks of households. Section 6 concludes. 


\section{LITERATURE REVIEW}

Evidence shows that wealth is less equally distributed than income. The reasons for this are manifold (for an overview, see for example Davies/Shorrocks 2000). Apart from an obvious existing variation in structural differences in terms of skills or fortune, and preferences in terms of saving and consumption behaviour, etc., which renders people more or less capable of making a fortune, wealth inequality is driven by two main sources. First, the accumulation of wealth takes time if achieved via saving out of income and investment of funds; hence over the lifecycle households have the chance to build up stocks of assets, which are then used as a tool to secure consumption levels in times of negative income shocks or lowered income levels after retirement. Thus we would expect a dispersion of wealth stocks according to age groups in the society. The second reason for wealth inequality is to be found in the intergenerational transmission of wealth via bequests or inter vivos gifts. The results of the research about which of the two reasons is more important in shaping the existing wealth distribution differ remarkably. In one of the first empirical papers on the topic, Kotlikoff/Summers (1981) summed up the amounts received as gifts or bequests by the current generation, capitalised those and yielded a figure for the present value of household wealth accruing from intergenerational transfers of 46 per cent in total wealth. In a later paper (Kotlikoff/Summers 1988) they summed up the difference between after-tax labour earnings and consumption expenditure over time, which they denoted as their estimate of aggregate lifecycle wealth, amounting to 19 per cent of total current household wealth in the United States at that time. The remaining 81 per cent of household wealth they claimed can be attributed to inheritance (including gifts). Modigliani (1988) by contrast argued that only about 20 per cent can be interpreted as such. The large divergence in the results of the cited studies stems inter alia from different views on which investments in the offspring (for example, education) can be interpreted as intergenerational inter vivos transfers, if household expenditure on durable goods is interpreted as consumption rather than saving and it depends on the degree of capitalisation of intergenerationally transferred wealth. Wolff (2002) estimates a share of 19-35 per cent (excluding investments in education of the offspring), using data from the US Survey of Consumer Finances between 1989 and 1998, while Gale/Scholtz (1994) assume that 51 per cent of the wealth is made up of transfers from ancestors, including trust accumulations and life insurance payments to children in inter vivos transfers but excluding college payments. Davies/Shorrocks (2000) believe that a reasonable rough estimate would be to assume the share of gifts and bequests in total wealth to amount to 35-45 per cent in the United States. For France, Kessler/Masson (1989) apply the approach of Kotlikoff/Summers (1981) and present a range of 35-46 per cent depending on the interest rate used for capitalisation of inheritance; while for Canada, Davies/St-Hilaire (1987), using the same approach, find results in a range of 35-53 per cent.

The literature on the links between wealth accumulation and inheritance claims that the distribution of household wealth strongly depends on the patterns of bequests or gifts made before the death of the bequeathers to their offspring. For the United States Wolff/Gittleman (2011) and for France Arrondel/Laferrere (2001) find that these wealth transfers are more concentrated than total wealth holdings in those countries.

In this paper I apply a decomposition approach, an analysis which has already a long tradition in the literature; to be more precise, I perform a decomposition by subgroups, including groups of households with different levels of inheritance and income received. Early applications and methodological analysis on income sources have been delivered by, for example, Fei et al. (1978), Fields (1979), Cowell (1980) and Shorrocks (1982). On decomposition by population subgroups, Theil (1972) was probably the first to deliver 
methods and was followed by Bourguignon (1979), Shorrocks (1980; 1984) and Foster/ Shneyerov (1996a; 1996b). However, regression-based methods such as the Shapley value approach were introduced somewhat later in the inequality literature, starting with Shorrocks (1999 - reprint 2013). In the section on methodology below I present the approach. Applications have been done by Fields/Yoo (2000) on labour income inequality in Korea, by Morduch/Sicular (2002) and Wan (2004) on income inequality in rural China, by Molini/Wan (2008) on Vietnam, and by Gunatilaka/Chotikapanich (2009) on expenditure inequality in Sri Lanka. Contrary to Shorrocks (1999), Fields (2003) estimates the share of the log variance of income that is attributable to explanatory factors. However, as Manna/Regoli (2012) point out (while applying the latter and the Shorrocks method to Italian income inequality), the Fields decomposition approach has the drawback of being limited to a log-linear functional form for the income generating function. A critical review of the Shapley value approach is delivered by Cowell/Fiorio (2009) and by Chantreuil/Trannoy (2013). Israeli (2007) shows how the Shapley approach is related to the method proposed by Fields (2003), who decomposes the $R^{2}$ of the underlying regression instead of the resulting inequality measure. The most important advantage of the Shapley value approach is that it takes the potential correlation amongst all regressors into account. More recently, Chernozhukov et al. (2009) and Fortin et al. (2010) have introduced applications of decomposition analysis based on counterfactual analysis. For a comparison of various (regression and non-regression based) methods of decomposition, see for example Heshmati (2004).

Most decomposition analyses have been performed on income inequality and its development over time; only some applications have been done so far on wealth inequality. Wolff (2002) decomposes the coefficient of variation in order to analyse the effect of bequests on wealth inequality in the United States in the 1990s. Brandolini et al. (2004) assess for Italy, and Azpitarte (2010) for Spain, that wealth inequality is mostly driven by inequality in real assets in contrast to financial wealth assets. Sierminska et al. (2010) study the drivers of the gender wealth gap in Germany, while Lindner decomposes wealth inequality by components for Austria (Lindner 2011) and other euro area countries (Lindner 2015) based on HFCS data. Sierminska/Doorly (2012) analyse the participation and wealth levels for chosen assets across households and show that household characteristics explain a sizeable portion of both wealth participation and wealth levels in a sample of European countries, the United States and Canada. However, no author has decomposed inequality of household wealth by subgroups, which is the aim of this paper, thus providing a novel contribution to the literature.

\section{DATA}

The data for the analysis presented in this paper are drawn from the Eurosystem Household Finance and Consumption Survey for the year 2010 (HFCS 2010 - UDB 1.1, published in February 2015), which was conducted in 15 euro area countries, ${ }^{1}$ while Estonia and Ireland are not included. Latvia and Lithuania were not yet members of the euro area at that time. A detailed description of the methodology of the survey is presented by the European Central Bank (2013). The HFCS provides data on gross and net wealth holdings of households and their components and socioeconomic characteristics for the

1. The HFCS 2010 was conducted in Austria, Belgium, Cyprus, Finland, France, Germany, Greece, Italy, Luxembourg, Malta, the Netherlands, Portugal, Spain, the Slovak Republic and Slovenia. 
households and their individual members. Moreover, it covers data on inheritance and gifts received and gross income. Interpreting results in cross-country comparisons of wealth inequality should be done cautiously. As discussed by, for example, Fessler/Schürz (2013) and Tiefensee/Grabka (2014), although a lot of ex-ante harmonisation was conducted (European Central Bank 2013), there are several aspects of potential methodological constraints regarding cross-country comparability due to non-harmonisation of sampling frames, sample sizes, survey modes, oversampling of top wealth households, reference periods, weighting or imputation methods applied and variations in initial response rates by countries. Nevertheless, as emphasised by Tiefensee/Grabka (2014: 26), 'the HFCS is still the best dataset for cross-country comparisons of wealth levels and inequality in the Euro area and it is definitely a first (big) step into the right direction'. The HFCS data offer five different multiple imputations in order to correct for item nonresponse. I take these imputations into account in my estimation analysis by using Rubin's Rule. Moreover, unit non-response is accounted for in the HFCS data by providing 1000 replicate weights, which are all used in my estimations.

In my analysis I decompose two different variables depicting wealth holdings of households: gross wealth (total household assets excluding public and occupational pension wealth) and net wealth (gross wealth minus total outstanding household liabilities). As explanatory variables I first apply total household gross income and five different types of inheritances and gifts (household main residence, further dwellings, land, business and the sum of other assets) received by all household members. Obviously, the net income of households would be a better measure of assessing the potential of households to save out of their income; moreover, present income may not be the best predictor of income flows accrued by individuals in their previous (working) life; however, this information is so far not available in the HFCS. In the HFCS 2010, the reference person is asked to provide information on whether the main household residence, if owned, was inherited or a gift. Furthermore, information is collected on up to three inheritances or substantial gifts from someone who is not a part of the current household. Since in the case of Finland no data were provided on inheritances, in the case of France no information was available on the means of acquisition of the household main residence (which could be a bequest or gift) and for Italy and the Netherlands respectively only 2.1 per cent and 6.7 per cent of all households provided information on inheritances (and gifts) received, I had to exclude those four countries from the analysis. Malta could not be included in the analysis either, owing to multiple data problems. In general, inheritance data have to be interpreted cautiously as inheritances are notoriously under-reported in wealth surveys. The rate of refusal to answer questions concerning inheritances especially rises in line with the wealth holdings of households (Fessler/Schürz 2013). Most probably this results in an underestimation of wealth inequality.

It should be pointed out that bequests and gifts acquired in the past are not automatically part of the actual present wealth stock. In the period between acquisition and the time of the survey interview, assets may have been used not only for the accumulation of the wealth stock of the household, but, for example, also for consumption purposes or inter-household transfers. Thus a regression of wealth stocks on wealth transfers received is not a means of explaining the total sum of wealth by its parts.

In addition to the value of the property at the time of acquisition (by way of inheritance or gift), information is collected on the date of acquisition. In order to make the assets inherited or acquired as gifts comparable with each other both within households and between households, we have to calculate the present value of the assets. The problem is dealt with in different ways in the literature; the resulting assumptions differ between a depreciation of the real value of assets (by leaving the nominal value of the acquired asset 
unchanged) and an appreciation of up to 3 per cent annually. For the lack of information on actual appreciation I resort to the conservative method applied by, for example, Fessler et al. (2008a; 2008b) and Fessler/Schürz (2013), assuming the retention of the real value of the asset by appreciation, using the annual national consumer price index (CPI). The data were provided by the AMECO database from 1960 onwards for all countries except for the Slovak Republic and Slovenia. Thus I excluded those two countries from the analysis as well. For assets acquired before 1960 I have to assume no increase in value up to 1960. Of those households having received inheritances and gifts, 1.5 per cent acquired them before 1960 (unweighted average over country shares). Concerning the application of the CPI for the calculation of the present value of the assets inherited or received as gifts I do not differentiate between different kinds of assets since households could swap between asset types. However, in the regression analysis I use the information of asset types to construct different explanatory variables. In the case of dwellings, land and businesses (including securities and shares) acquired, I assume that households have a higher incentive to keep those assets and further invest in them, and that those assets appreciate with an interest rate exceeding the CPI (the applied appreciation rate for bequests and gifts) resulting in higher wealth stocks of households having inherited those assets. Thus the present value of the following groups of assets acquired via inheritance (or as gift) were used as separate explanatory variables: household main residence; dwellings apart from household main residence and use of dwellings; land; businesses (including farms), securities and shares; further assets inherited (or received as gifts). The latter group of assets also includes the values of those inheritances (or gifts) which comprise more than one specific asset, since in such cases the value of individual assets is not provided for in the HFCS data file. ${ }^{2}$ Some information that was used as an additional explanatory variable was not collected in all euro area countries. This was the case for the question of expectations on the receipt of a substantial gift or inheritance in the future for Spain.

Furthermore, I use socioeconomic characteristics as explanatory variables. For this I employed personal characteristics of the household members in order to construct variables for the household level. These are: the household level of educational attainment; the average age of adult household members (being more than 19 years of age); and the household size, that is to say the number of adults and children in the household. Moreover, I used dummies for the marital status of the household reference person (being single, married, widowed, divorced or living in a consensual union on a legal basis). The reference person of the household provided in the HFCS - UDB 1.1 data file version (variable DHIDH1) is chosen according to the 'Canberra' definition. ${ }^{3}$ The household level of educational attainment is calculated as the average attainment level (expressed in average years of schooling needed to attain the education level stated for the individual household members) of all household members above the age of 16 and no longer in education (and thus potentially available for the labour market). The use of socioeconomic characteristics is particularly important in the case of cross-country comparisons since differences in household structures have a substantial effect on the measured summary statistics of wealth distribution in the euro area (see for example Fessler et al. 2014). For instance, I expect that households

2. In the case of Belgium, 57 per cent of the present value of inheritances and gifts could be assigned to one of the five specific groups of assets described above (that is, the rest of the value had to be assigned to the category 'other assets'). For further countries analysed: ES: 66 per cent, LU: 71 per cent, AT: 80 per cent, DE: 82 per cent, PT: 84 per cent, CY: 93 per cent, GR: 94 per cent.

3. The procedure of identification of the reference person is described in United Nations Economic Commission for Europe (2011: 65). 
with more members, with higher average education levels and whose members have a higher average age tend to possess higher stocks of gross and net wealth.

\section{METHODOLOGY}

The advantage of a regression-based approach is that the relative importance of many variables and groups of them to explain inequality (socioeconomic characteristics of individuals or households such as age, gender, educational attainment and employment status, as well as decisive monetary values such as income, etc.) is taken into account simultaneously. Thus, the regression approach (step 1) allows us to assess the importance of each of these explanatory variables, conditional on all other variables for any dimension of inequality considered (in my case stocks of household gross and net wealth). The Shapley value approach (step 2) then allows us to further calculate the contribution of each of these explanatory variables to the respective inequality measure.

The Shapley value approach can be illustrated by using a simple example with three explanatory variables. I first regress individual wealth levels $y$ on these explanatory variables $x_{i}(i=1,2,3)$ :

$$
y=\beta_{0}+\beta_{1} x_{1}+\beta_{2} x_{2}+\beta_{3} x_{3}+\varepsilon
$$

where $\varepsilon$ denotes the error term. The predicted wealth level is then given by

$$
\widehat{y}_{123}=\widehat{\beta}_{0}+\widehat{\beta}_{1} x_{1}+\widehat{\beta}_{2} x_{2}+\widehat{\beta}_{3} x_{3} .
$$

This predicted value is then used to calculate the Gini coefficient $\widehat{G}_{\{123\}}^{(0)}$, where subscripts denote the variables included. In the first round I then eliminate one variable and calculate the predicted wealth levels $\widehat{y}_{\{23\}}, \widehat{y}_{\{13\}}$ and $\widehat{y}_{\{12\}}$ for each household using the vectors of $x_{i}$ and the original coefficients $\beta_{i}$ from my wealth estimation (see step 1 of the approach). The corresponding Gini coefficients are then given by $\widehat{G}_{\{23\}}^{(1)}, \widehat{G}_{\{13\}}^{(1)}$ and $\widehat{G}_{\{12\}}^{(1)}$ respectively. Analogously, in a second round I eliminate two variables, thus calculating $\widehat{y}_{\{1\}}, \widehat{y}_{\{2\}}$ and $\widehat{y}_{\{3\}}$. The resulting Gini coefficients are $\widehat{G}_{\{1\}}^{(2)}, \widehat{G}_{\{2\}}^{(2)}$ and $\widehat{G}_{\{3\}}^{(2)}$. The final round would then be to include the constant only; the resulting Gini coefficient would thus be $\widehat{G}_{\{\}}^{(3)}=0$.

The marginal contributions are then calculated using the Gini coefficients. The first round marginal contributions for each variable are $C_{1}^{(1)}=\widehat{G}_{\{123\}}^{(0)}-\widehat{G}_{\{23\}}^{(1)}, C_{2}^{(1)}=$ $\widehat{G}_{\{123\}}^{(0)}-\widehat{G}_{\{13\}}^{(1)}$ and $C_{3}^{(1)}=\widehat{G}_{\{123\}}^{(0)}-\widehat{G}_{\{12\}}^{(1)}$.

The marginal contributions in the second round of the first variable are given by

$$
C_{1}^{(2,1)}=\widehat{G}_{\{12\}}^{(1)}-\widehat{G}_{\{2\}}^{(2)} \text { and } C_{1}^{(2,2)}=\widehat{G}_{\{13\}}^{(1)}-\widehat{G}_{\{3\}}^{(2)} .
$$

The average of these contributions is the marginal contribution of the first variable in the second round; that is, $C_{1}^{(2)}=\frac{1}{2}\left(C_{1}^{(2,1)}+C_{1}^{(2,2)}\right)$. Similarly, I calculate $C_{2}^{(2)}$ and $C_{3}^{(2)}$. The third-round contribution is given by $C_{1}^{(3)}=\widehat{G}_{\{1\}}^{(2)}-\widehat{G}_{\{\}}^{(3)}=\widehat{G}_{\{1\}}^{(2)}$ as $\widehat{G}_{\{\}}^{(3)}=0$ and analogously for $C_{2}^{(3)}=\widehat{G}_{\{2\}}^{(2)}$ and $C_{3}{ }^{(3)}=\widehat{G}_{\{3\}}^{(2)}$. 
Finally, averaging the marginal contributions of each variable over all rounds, $j=1,2,3$ results in the total marginal effect of each variable, that is:

$$
C_{j}=\frac{1}{3} \cdot\left(C_{j}^{(1)}+C_{j}^{(2)}+C_{j}^{(3)}\right)
$$

The proportion of inequality not explained is then given by

$$
C_{R}=G-\widehat{G}_{\{123\}}^{(0)} .
$$

The approach can easily be extended to any number of explanatory factors and to other inequality measures. However, as the number of combinations and thus Gini coefficients to be calculated grows exponentially with the number of variables, in practice is it necessary to combine the variables to seven or eight explanatory factors in order to keep the necessary computing time tolerable. In my case I included in the explanatory factor 'inheritance' the effect of the individual types of bequests and gifts and the effect of expected inheritance; the factor 'household age' includes the variable 'household age' and its squared term; 'household structure' includes the effect of both the variables 'number of adults' and 'number of children'; and the explanatory factor 'marital status' comprises the effect of all three dummy variables for single, widowed and divorced reference persons of households (comparing their wealth holdings with those of reference persons being married or living in a consensual union).

Wan (2002) points to the fact that the presence of a negative constant in the regression equation may lead to negative predicted individual income levels. In that case the calculation of a Gini coefficient and thus the contributions of individual variables to overall inequality would be impossible. To overcome this pitfall, Wan (ibid.) shows that different model specifications can be used for the underlying estimated income (in my case, wealth) generating function, delivering moreover better log-likelihood values than the linear estimation model. Following his approach, I choose for the analysis in this paper a semilog model:

$$
\ln y=\beta_{0}+\beta_{1} x_{1}+\beta_{2} x_{2}+\beta_{3} x_{3}+\varepsilon .
$$

As the distribution of wealth data is not only highly skewed but net wealth data also comprise, due to outstanding debts of households, negative and zero values, we cannot apply a logarithmic transformation of the data, but must resort to a transformation often used in the literature on wealth stocks (see for example Burbidge et al. 1988; MacKinnon/Magee 1990; Pence 2006; Schneebaum et al. 2014), namely the inverse hyperbolic sine transformation (IHS):

$$
y_{i}=\operatorname{IHS}\left(W_{i}\right)=\ln \left(W_{i}+\sqrt{W_{i}^{2}+1}\right) .
$$

This transformation is used not only for the wealth stocks but also the calculated sums of inheritances and gifts and the income of households, as both can also feature zero and the latter for self-employed income also negative values. Thus my semilog model takes the form:

$$
\ln y=\ln \left(W+\sqrt{W^{2}+1}\right)=\beta_{0}+\beta_{1} x_{1}+\beta_{2} x_{2}+\beta_{3} x_{3}+\varepsilon .
$$


As we are not interested in the decomposition of the log of net wealth, but net wealth in nominal terms, in the second step of the decomposition analysis I calculate the fitted values for the wealth levels of households after taking the antilog of the above model, resulting in:

$$
e^{\ln \hat{y}_{i}}=e^{\hat{\beta}_{0}} *\left(e^{\hat{\beta}_{1}}\right)^{x_{1 i}} *\left(e^{\hat{\beta}_{2}}\right)^{x_{2 i}} *\left(e^{\hat{\beta}_{3}}\right)^{x_{3 i}},
$$

where $\widehat{\beta}_{i}$ denotes the coefficients of the estimated regression (3). In my case, after the above-described IHS transformation, this results in:

$$
\widehat{y}_{i}=\widehat{W}_{i}+\sqrt{\widehat{W}_{i}^{2}+1}=e^{\hat{\beta}_{0}} *\left(e^{\hat{\beta}_{1}}\right)^{x_{1 i}} *\left(e^{\hat{\beta}_{2}}\right)^{x_{2 i}} *\left(e^{\hat{\beta}_{3}}\right)^{x_{3 i}} .
$$

The advantage of this model is that in this case the constant $e^{\hat{\beta}_{0}}$ now becomes a positive scalar which does not influence the magnitude of the calculated Gini coefficient. The elimination procedure as described above, however, remains unchanged. As one can see, we approximate wealth inequality with the transformed fitted values of the household wealth levels $\widehat{W}_{i}+\sqrt{\widehat{W}_{i}^{2}+1}$ stemming from $e^{\ln \left(\widehat{W}_{i}+\sqrt{\widehat{W}_{i}^{2}+1}\right)}$ instead of $\widehat{W}_{i}$. This would only be problematic if we had a large number of negative predicted values. However, since in my sample this is only the case in about 4 per cent of the cases (with mostly low absolute values), the inequality levels calculated are almost the same based either on $\widehat{W}_{i}+\sqrt{\widehat{W}_{i}^{2}+1}$ or $\widehat{W}_{i}$.

\section{EMPIRICAL RESULTS}

In order to describe the situation of wealth distribution in the analysed countries, I start by taking a look at the inequality of income and wealth holdings across countries. Table 1 presents the Gini indices of wealth assets of households. We can observe that both gross and net wealth are distributed much more unequally compared to household gross income. Moreover, the Gini indices for wealth holdings are much higher in Austria and Germany, while lowest in Spain, Greece and Belgium. Bequests and gifts at present value are even more unequally distributed than net wealth. Taking into account the underreporting of inheritances, the inequality of bequests may be even higher. This is an effect of the relatively low rates of households having acquired an inheritance (or substantial gift) up to the date of the survey. In Portugal only an estimated 26.5 per cent of all households received bequests, while in Austria the share is 35.2 per cent.

\subsection{Regression analysis}

Following the above-described approach of the Shapley value decomposition I first regress the IHS-transformed gross wealth assets of the household on the explanatory variables (for a detailed description of those see the section on data above). In my case these are the present values of five different groups of specific asset types inherited or acquired as gifts, a dummy for the expectation of future substantial bequests or gifts, 


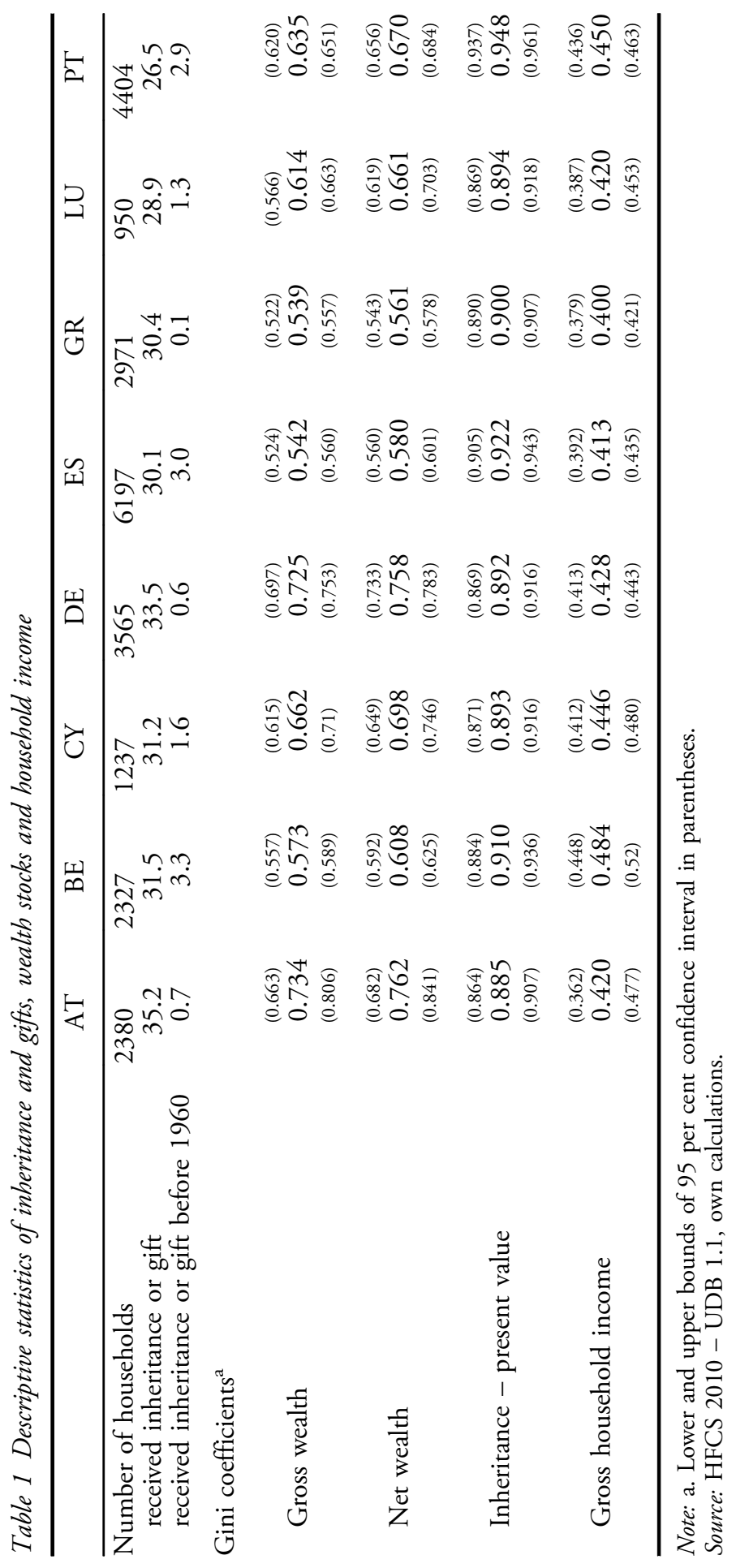


gross household income and a set of socioeconomic characteristics: ${ }^{4}$ the average age of the adult household members (and the square of this variable), the average education level of the adult household members and the number of adults and children in the household. Moreover, I apply dummies for the marital states of the reference person of the household. I expect wealth holdings of households to increase conditionally on amounts of inheritances (and substantial gifts) acquired and household gross income respectively.

The results presented in Table 2 show that in general the coefficients are of the expected signs in the regressions and significant for a large part of the explanatory variables in most countries. The explained part of the variance amounts to 34 per cent on average (unweighted over countries) as shown by the $R^{2}$. For those three asset types, being most important in total value of inherited wealth on average (household main residence, land and further dwellings), the positive conditional correlation with gross wealth stocks is highest for Germany and Austria. An interesting result is that the incidence of having inherited a business does not significantly alter the conditional accumulation behaviour (more precise results) of households in all countries, that is, in Austria, Cyprus and Portugal.

The higher the average age of the household, the more the members had time to accumulate wealth holdings. Coefficients for age and age ${ }^{2}$ show that household gross wealth rises with increasing average age of the (adult) household members; however, no significant results concerning age could be found for Germany and Luxembourg. For most countries on average, the conditional peak of wealth holdings is reached at about 55 years (average age of adult household members). Households with higher average education levels hold conditionally higher gross wealth stocks. In general larger households seem to have the possibility of accumulating higher wealth stocks. Only in the case of Portugal are significant results available for the number of children in the household. More children in the household correlate with lower levels of gross wealth holdings. As expected, households where the reference person is married or lives in a consensual union have conditionally higher wealth stocks compared to all other households. For completeness I should also mention here that in an earlier version of the regression model I also included the gender of the reference person as an explanatory variable and the share of female members in households. However, the results were non-significant.

In addition to gross wealth holdings of households I also regress net wealth holdings on the above-described explanatory variables. The results, reported in Table 3, are similar to those for household gross wealth. Coefficient signs remain in general the same, whilst the share of the explained variance drops to an $R^{2}$ of some 18 per cent. This is no surprise since the underlying decisions of households to borrow money for private or business purposes are even more influenced by reasons difficult to describe with the information available from the HFCS. In general, the signs of the coefficients do not change and remain significant in almost all cases. The size of the coefficients increases for most variables throughout the majority of countries, particularly for inheritance (and gifts) and household income, but also in the case of household age, education level and number of adults in the household. For single and widowed reference persons the coefficients become

4. Obviously one could apply different explanatory variables particularly for detecting the influence of household characteristics. In a robustness check I also used alternatively the household-type dummies applied by Fessler et al. (2014). The results concerning the contributions of inheritance and gifts, income and education remained robust. The advantage of my set of explanatory variables is that I can identify the individual effects of age, number of adults and children and marital status of reference persons, which are in the case of the above-mentioned household-type dummies intermingled. 


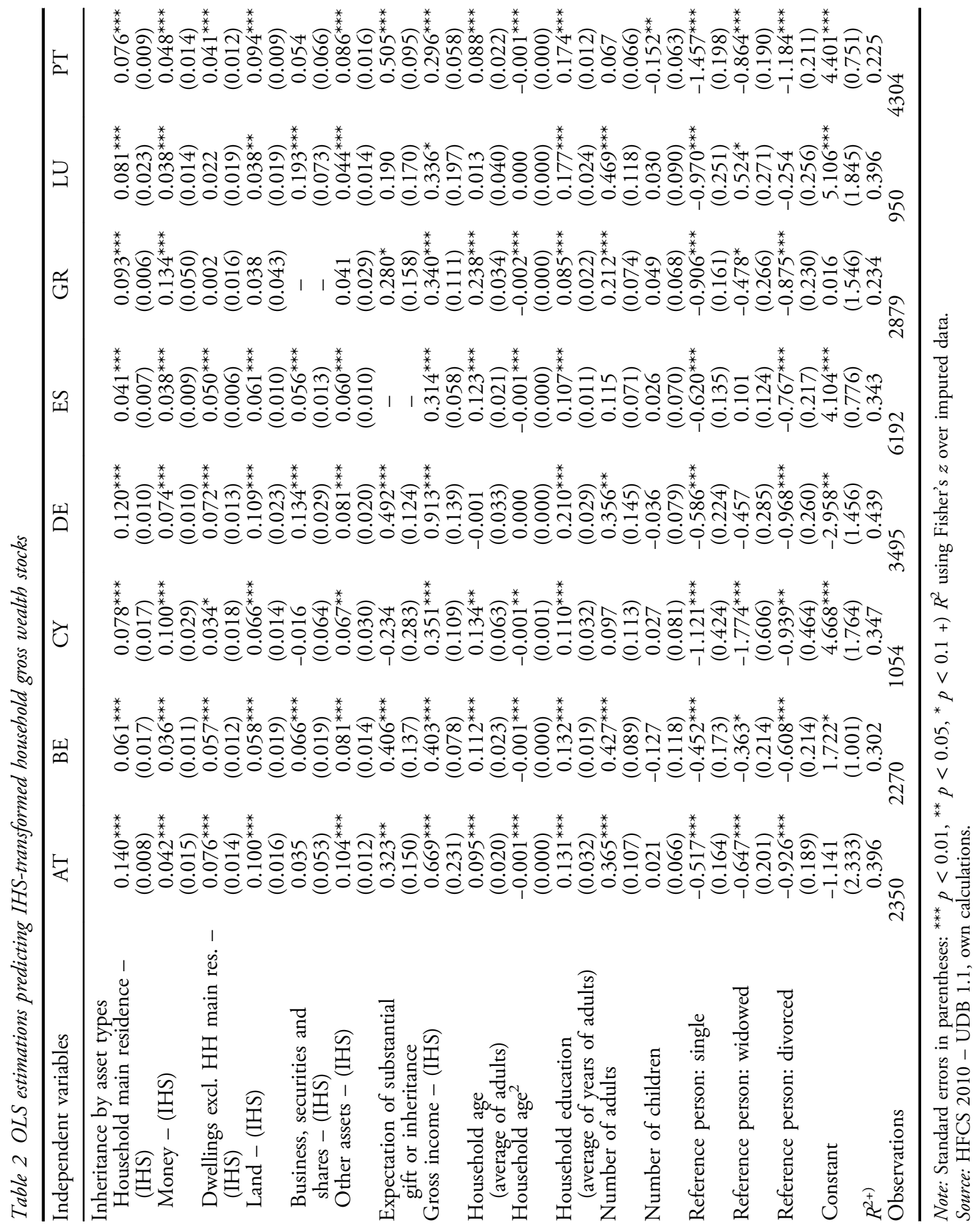


126 European Journal of Economics and Economic Policies: Intervention, Vol. 13 No. 1

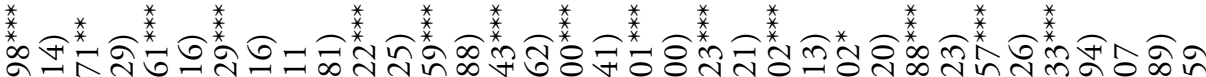

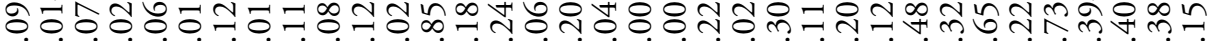
ó

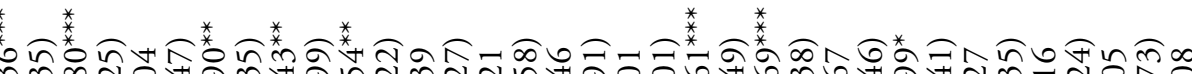

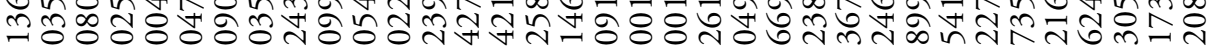
-

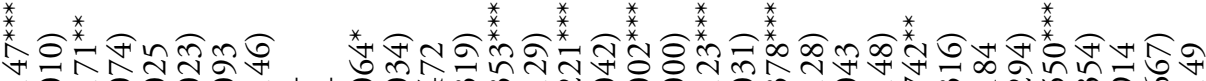

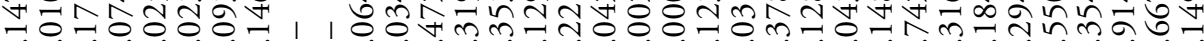

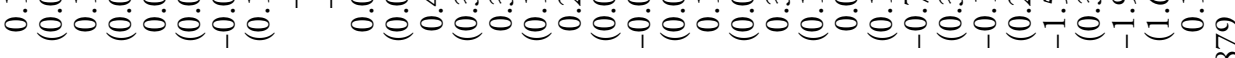

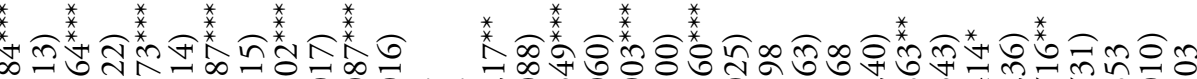

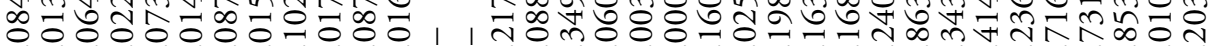
$\dot{0} \dot{0} \dot{0} \dot{0} \dot{0} \dot{0} \dot{0} \dot{0}$ ó

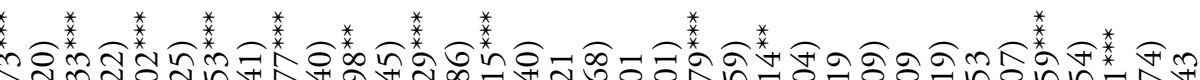

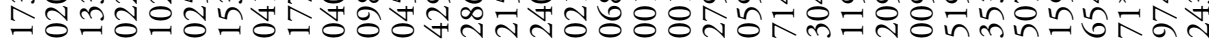

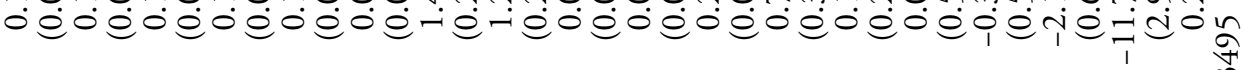

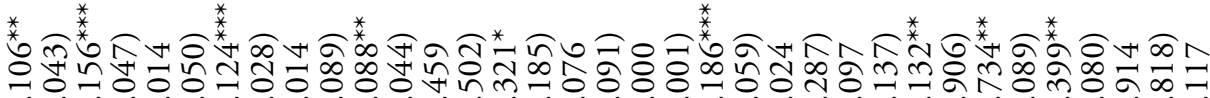

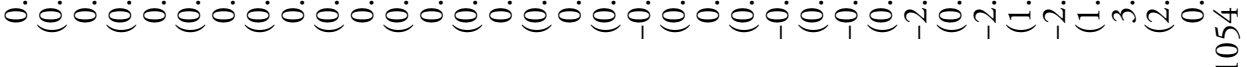

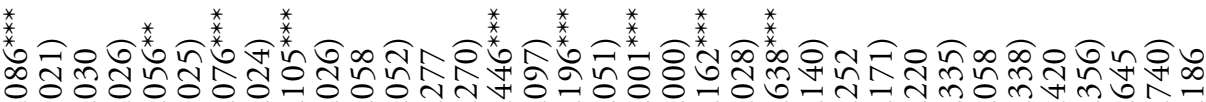

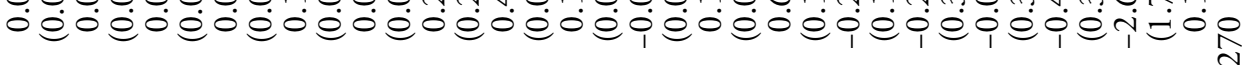

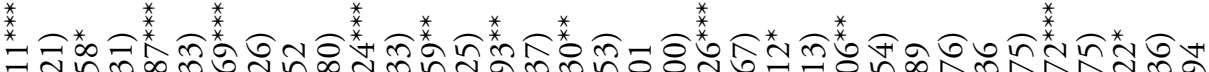
สై์

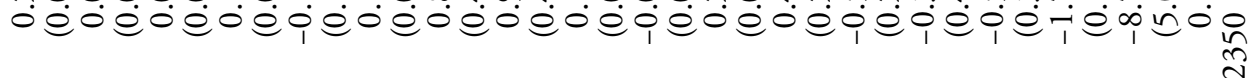

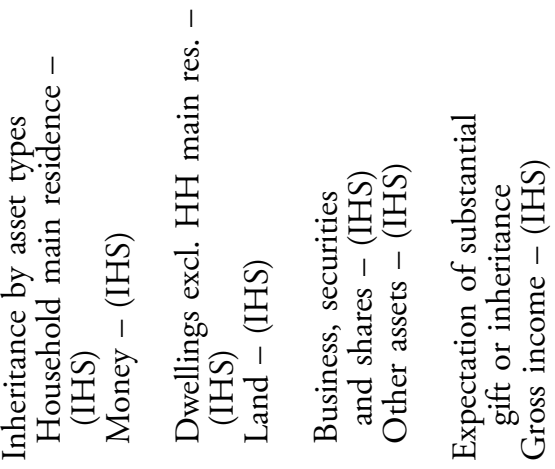

(C) 2016 The Author

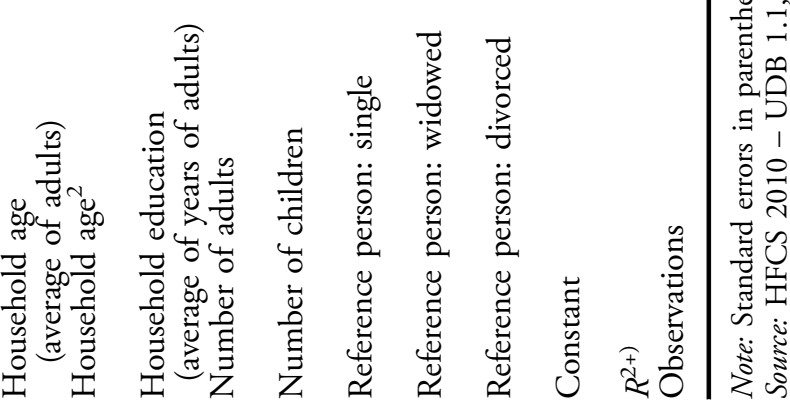


insignificant in a couple of countries while for households with divorced reference persons the value of the negative coefficient rises in most countries.

\subsection{Shapley value decomposition}

Now we turn from the explanation of household wealth levels to the explanation of national wealth inequality levels by applying the Shapley value approach to inequality decomposition. Figure 1 presents the decomposition results for gross household wealth. First, we see that the Gini index calculated from the predicted values of the wealthgenerating function is quite similar to the one based on the original wealth holdings of households. Only in the case of Germany is wealth inequality somewhat overestimated, for Spain somewhat underestimated.

From the explanation of the methodology above, one can derive that the extent to which an explanatory factor or variable contributes to the Gini coefficient depends, first, on the dispersion of wealth holdings between the household subgroups being defined by the characteristics described by the variables and, second, on the shares of the subgroups in the total population. In my case, in order to keep the computing time of the Shapley value analysis tolerable, I collapsed the effects of the individual types of bequests and gifts and the effect of expected inheritance to the explanatory factor inheritance and gifts; the factor 'household age' includes the variables 'household age' and 'household age $^{2}$; 'household structure' includes the effect of both the variables 'number of adults' and 'number of children', and the explanatory factor 'marital status' comprises the effect of all three dummy variables for single, widowed and divorced reference persons of households.

In the case of the decomposition of gross wealth we can observe that for the countries analysed on average almost 45 per cent of the wealth inequality can be explained by the variation of gross income and acquired bequests and gifts (see Figure 2). Thus the

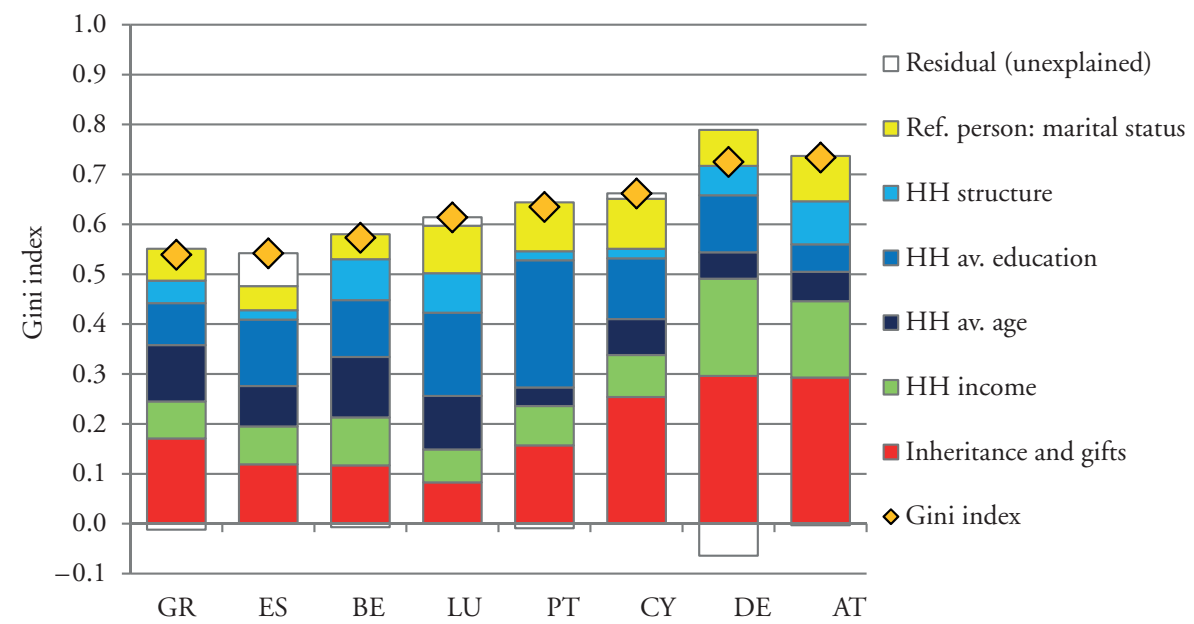

Source: HFCS 2010 - UDB 1.1, wiiw calculations.

Figure 1 Shapley value decomposition (gross wealth): contribution of groups of explanatory variables to Gini index 


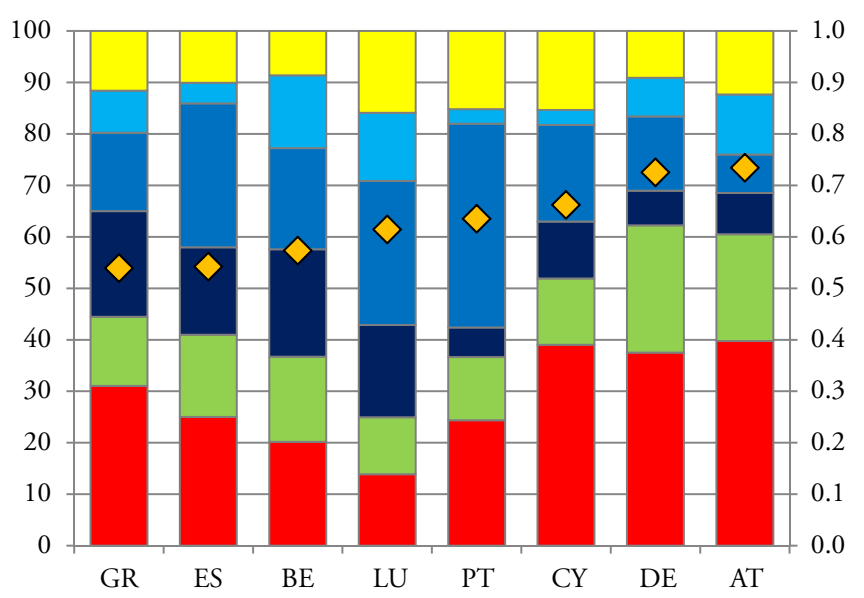

$\square$ Ref. person: marital status

口 $\mathrm{HH}$ structure

n $\mathrm{HH}$ av. education

- $\mathrm{HH}$ av. age

$\square \mathrm{HH}$ income

Inheritance and gifts

$\diamond$ Gini index (right scale)

Source: HFCS 2010 - UDB 1.1, wiiw calculations.

Figure 2 Shapley value decomposition (gross wealth): contribution of groups of explanatory variables to explained inquality, in \%

differences in the accumulation of wealth stocks are significantly driven by the variations in household characteristics. However, the results differ strongly between countries. In Austria, Cyprus and Germany, the countries with the highest levels of inequality of gross wealth, the inequality of inheritances is the most important driver of overall wealth dispersion - almost 40 per cent of the explained inequality stems therefrom. However, in relative terms (as a share of the overall explained inequality), also in the case of the country with the lowest level of dispersion in gross wealth (that is, Greece), 30 per cent of the Gini coefficient can be explained by the inequality of inheritances. The lowest contribution of inheritances to the overall Gini index - only 14 per cent of the explained variation - can be found in Luxembourg, most likely a combination of relatively low inequality of inheritances and a low share of households having received bequests at all. In the rest of the countries analysed, inheritances explain between 20 per cent and 25 per cent of the Gini index. A noticeable divergence between Germany and Austria on the one hand and all other countries analysed can be observed in the case of the contribution of household gross income.

In Germany and Austria, household income explains 25 per cent and 21 per cent respectively of the inequality level, while the average contribution for all other EU members analysed amounts to only 14 per cent. Even stronger differences can be detected according to the contributions of the average education level of households. This fits well with the differences in dispersion of household education levels across countries. Within the European Union, Portugal features the highest level of inequality in educational attainment rates (see for example Leitner/Stehrer 2014), while particularly low dispersion according to this characteristic is to be found in Germany and Austria. Also, the ranking of the other countries in the Shapley decomposition corresponds with the one according to educational inequality between households, with the exception of Greece. In Portugal the dispersion in education is the main single driver of wealth inequality, explaining 40 per cent of the Gini index. In Spain and Luxembourg, 28 per cent of the explained variations still stems from education and in all other countries the 
contribution ranges between 14 per cent and 20 per cent, except for Austria. In the latter country educational differences account for only 7 per cent of the dispersion of gross wealth stocks. In the case of the average age of the household members, one can see that the contribution to total inequality does not only depend on the conditional effect age has according to the regression analysis on wealth holdings. Also, the differences between countries in the actual age structure of the population and thus the relative size of the age groups influence the decomposition results. In Germany, Austria and surprisingly also Portugal, the contribution of age is quite low, adding between 6 per cent and 8 per cent to the Gini index. In all other countries, variation by average age of household members seems to be contributing more strongly to overall wealth inequality, between 11 per cent and 21 per cent. As we could already expect from the underlying regression analysis, gross wealth does not significantly differ conditional on all other explanatory variables between households of different size in Portugal, Spain and Cyprus. Hence, the size of the contribution amounts to 2.8 per cent, 2.9 per cent and 4 per cent in those three countries. In Luxembourg, Belgium and Austria, where differences in the structure of households are more important in explaining wealth inequality, the contribution ranges between 12 per cent and 14 per cent of the explained inequality. Wealth differences due to the marital status of the reference person are relatively low in Belgium and Germany (both 9 per cent) but substantially higher in the Southern European countries of Portugal and Cyprus (both 15 per cent) and Luxembourg (16 per cent). In all other countries the contribution ranges between 10 per cent and 12.5 per cent.

The subsequent step in the analysis is the decomposition of the net wealth of households. A glance at Figure 3 shows that the results look quite similar to the decomposition of gross wealth holdings. However, my wealth-generating functions stemming from the regressions by country presented in Table 3 lead to an overestimation of inequality in household net wealth in all countries analysed. Looking into the detailed results for net wealth holdings by quantiles, we can detect that the highest relative differences between predicted and original values are between the 40 th and 60 th percentile for most countries.

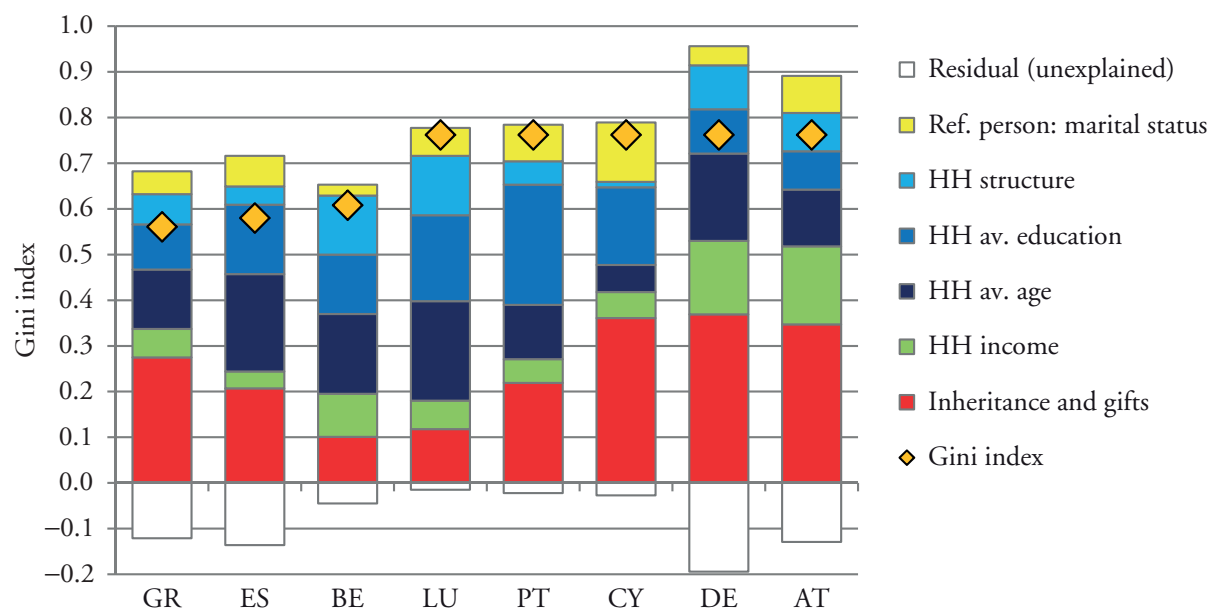

Source: HFCS 2010 - UDB 1.1, wiiw calculations.

Figure 3 Shapley value decomposition (net wealth): contribution of groups of explanatory variables to Gini index 
Here we tend to underestimate the amounts of net wealth holdings. Thus the cross-country comparisons of absolute contributions of explanatory variables to the Gini coefficient have to be handled with care, while the comparison of the shares in the explained (calculated) inequality is less problematic. Although in absolute terms the contributions of bequests and gifts are still highest in Cyprus, Austria and Germany, in relative terms it is also the case that in Greece inheritance accounts for about 40 per cent of the explained inequality in net wealth of households (see Figure 4). In Spain and Portugal the contribution is close to 30 per cent, while in Luxembourg and Belgium it amounts to about 15 per cent in each case. For household income the contributions are again relatively large in Germany (17 per cent) and Austria (19 per cent) and are also remarkable in Belgium (14 per cent). In all other countries they range in between only 6 per cent and 9 per cent of total inequality. The ranking of the contributions of the average education level of households is comparable to the decomposition of gross wealth as well as the shares in the explained inequality. In Austria, Germany and Greece they amount to, on average, 11.5 per cent, while in Portugal they amount to 34 per cent. In the rest of the countries the share ranges between 20 per cent (in Belgium) and 24 per cent (in Luxembourg).

Age differences between households are more important in the explanation of net wealth compared to gross wealth holdings of households. An important reason for this is most likely to be found in the higher debt level of younger-aged persons and the life cycle of saving and investment. Only in the case of Cyprus is the contribution below 10 per cent; in the other countries the share ranges between 14 per cent in Austria and 30 per cent in Spain. The contribution of household structure is small, particularly in the case of Cyprus (1.5 per cent), but also for Spain and Portugal (both 6 per cent), while in the rest of the analysed countries it ranges between 9 per cent and 17 per cent. Only in Belgium do household size differences account for about 20 per cent of the total Gini index. On average the explanatory power of the marital status of the reference person is somewhat smaller compared to the case of gross wealth. However, differences between countries are larger in this respect. While in Germany and Belgium only 4 per cent of inequality in net wealth is explained by those explanatory variables, in Cyprus the respective contribution amounts to almost 17 per cent.

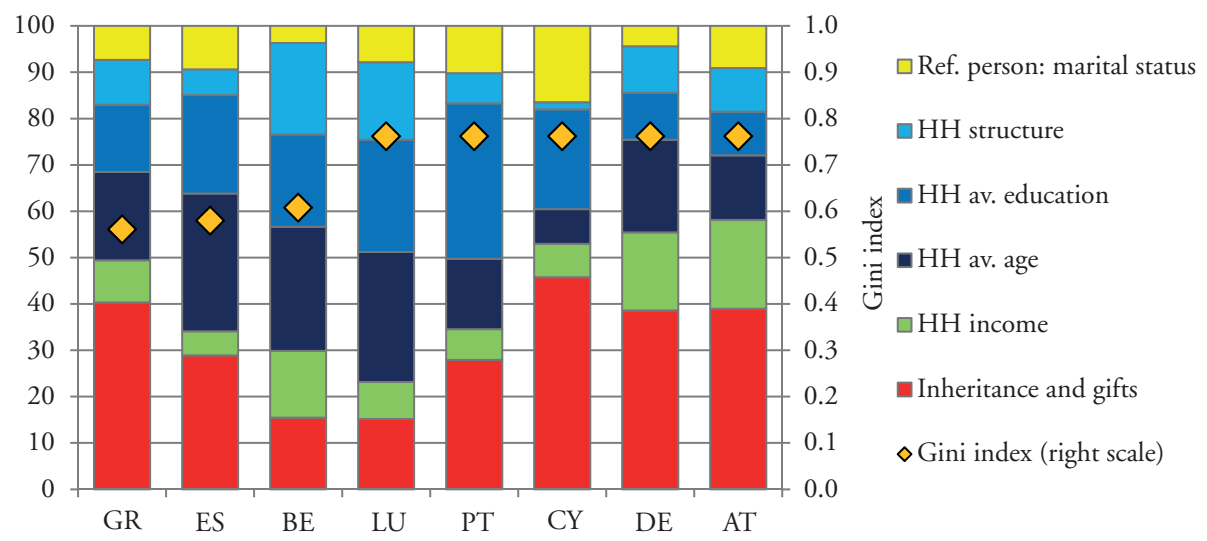

Source: HFCS 2010 - UDB 1.1, wiiw calculations.

Figure 4 Shapley value decompositon (net wealth): contribution of groups of explanatory variables to explained inequality, in \% 


\section{SUMMARY AND CONCLUSIONS}

In this paper I have analysed inequality in gross and net wealth stocks of households in selected euro area countries (Austria, Belgium, Cyprus, Germany, Greece, Luxembourg, Portugal and Spain) in comparison. The analysis is based on micro data from the Eurosystem Household Finance and Consumption Survey 2010 (HFCS 2010 - UDB 1.1). Other countries also covered in the HFCS 2010 unfortunately had to be skipped due to incomplete coverage of data on inheritance or a lack of CPI data (Finland, France, Italy, Malta, the Netherlands, the Slovak Republic, Slovenia). In order to detect the sources and drivers of wealth inequality I apply the Shapley value approach to decomposition analysis.

Wealth inequality is much higher compared to inequality in income. The comparison of euro area countries shows that inequality levels of wealth are highest in Austria and Germany, whilst relatively low in the Southern European countries Spain and Greece but also in Belgium. The building-up of household wealth stocks takes place via saving and investment out of two sources in particular. First, households save out of their current income from paid and self-employment as well as from financial income. Second, bequests and inter vivos gifts are important transfers of assets that are likely to be used for wealth accumulation particularly by those households that are in no need to use those funds for consumptive purposes.

My decomposition analysis focuses on the extent to which those two types of sources of wealth accumulation shape the levels of wealth inequality in the euro area countries in comparison and in addition to what extent the inequality can be attributed to differences in household characteristics. First, I regress gross and net wealth holdings of households on the values of different types of assets acquired by households as substantial bequests or gifts and on current gross household incomes. In addition I apply variables describing socioeconomic characteristics averaged over household members, that is to say the average age of adult household members, the average of highest education level attained by those household members being potentially available for the labour market, and the number of adults and children in the household. I also use dummy variables for the marital status of the reference person of the household (married or living in a consensual union, single, widowed or divorced). In order to make bequests and gifts acquired at different points in time comparable with each other and between households, I make the conservative assumption that the real values of the items do not change over time. Thus I inflate the nominal values of bequests and gifts with the national consumer price indices. For the analysis of how much the income of a household has influenced the wealth stock built up, it would be preferable to have information on the previous income over the whole life cycle for all household members. However, this information is not available in the HFCS 2010 and I have to apply the current gross household income as a proxy for lifetime income. Moreover, the household age captures the cohort effect, that is to say older individuals/households have had the chance to accumulate more wealth compared to younger ones. For my regressions I apply an inverse hyperbolic sine transformation to all monetary variables, which approximates the logarithmic transformation in order to raise the fit, however without losing negative and zero values which are numerous in wealth data.

My regressions deliver the expected results with respect to the signs of the coefficients and are significant for most of the variables in the majority of countries. Households with higher amounts of bequests and inter vivos transfers acquired over the previous lifetime feature conditionally higher levels of gross and net wealth stocks. Those with higher current household income obviously have more funds available for non-consumptive 
purposes and have thus accumulated relatively high wealth holdings. Contrary to my assumption, the incidence of having inherited a business, securities or shares does not increase (conditionally) the tendency to hold higher asset levels in all countries - in Austria, Cyprus and Portugal no significant results were found. The present value of inheritance being a business, securities or shares is, in the case of three countries (BE, $\mathrm{DE}$ and $\mathrm{LU}$ ) and on average over all countries, the strongest driver of gross wealth and net asset holdings; in the latter case also for Spain. Second-most important is on average the household main residence and third is inherited land. The expectation of a substantial inheritance or gift in the future correlate positively with gross wealth levels in five out of seven countries for which the variable was available; for net wealth levels only in the case of Austria, Germany and Portugal. The cumulative process of building wealth stocks results in households with higher average age having conditionally higher real estate wealth stocks, whilst for Germany and Luxembourg these results are not robust in the case of gross and net wealth holdings, for Cyprus in the case of net wealth holdings. The effect declines over the life cycle and household gross wealth peaks conditionally on average over countries at a mean household age of about 55 years. Average household education levels correlate conditionally positively with wealth stocks. The variable might also capture some of the longer-term income differences between households, which are not embodied in the differences of current household income. Households with more adults in general hold conditionally more wealth assets. However, this result is not significant for both types of wealth holdings analysed in the case of Cyprus and Spain and for gross assets in the case of Portugal. The motive of accumulating wealth for later transfers to the offspring seems to be strong as reported in the literature. Thus households with more children might have conditionally higher wealth holdings. However, in the regressions the coefficients for number of children are insignificant or the opposing trend - that more children in the household prevent the accumulation of more out of the given funds due to current needs - seems to dominate. Households with reference persons who are are single, widowed or divorced have conditionally lower gross wealth holdings; the effect, however, becomes insignificant for a single household in the case of net wealth holdings.

Based on the wealth-generating functions stemming from my regressions, I applied the Shapley decomposition analysis. Gini coefficients were calculated for predicted values of wealth holdings of individual households stemming from all combinations of explanatory variables. The average differences between those Gini indices resulted in the estimation of the marginal contribution of each explanatory variable to the overall Gini of wealth stocks. In order to keep the necessary computing time tolerable, I collapsed the effect of a couple of variables to explanatory factors. These were the individual types of bequests and gifts and the effect of expected inheritance to the explanatory factor inheritance and gifts; the variables 'household age' and 'household age ${ }^{2}$ ' to the factor 'household age'; the factor 'household structure' includes the effect of both the variables 'number of adults' and 'number of children', and the explanatory factor 'marital status' comprises the effect of all three dummy variables for single, widowed and divorced reference persons of households (comparing their wealth holdings with those of reference persons being married or living in a consensual union).

On average over the countries analysed, bequests and gifts contribute about 29 per cent to the predicted inequality of gross wealth stocks and 31 per cent to the distribution of net wealth holdings. The contribution of gross household income is lower, with 16 per cent and 11 per cent respectively. However, the results vary considerably between countries. Austria, Cyprus and Germany show the highest share ( 40 per cent, 39 per cent and 38 per cent) for gross assets, while for net assets Cyprus features the highest contributions with 46 per cent to the explained inequality. In the case of net wealth, Austria, Germany and Greece feature 
shares of about 40 per cent, while the figures for Portugal and Spain but especially Belgium and Luxembourg are much lower. The contribution of income to both gross and net wealth inequality is relatively high in Austria ( 21 per cent and 19 per cent respectively), Germany ( 25 per cent, 17 per cent) and Belgium (17 per cent, 14 per cent). In the other countries the share amounts on average to only 13 per cent in the case of gross wealth inequality and to 7 per cent for net wealth inequality. The results of the decomposition analysis show that differences in household characteristics are an important source of wealth inequality. Average age and education levels contribute about 19 per cent each to the overall Gini index of net wealth, while in the case of gross wealth, education is (with 21 per cent) more important compared to the average household age (13 per cent). Differences in the size of households make a contribution of 8 per cent and 10 per cent to gross and net wealth inequality, respectively. The fact that the reference person of a household is not married or living in a consensual union has an effect that contributes, on average over countries, 12 per cent and 9 per cent to the inequality of gross and net wealth stocks, respectively.

The analysis in this paper reveals that differences in the amount of bequests and inter vivos gifts received by households strongly drive the observed wealth inequality in a number of euro area countries. In Austria, Germany and Cyprus those differences contribute about 39 per cent to the explained inequality of gross wealth, while for net wealth dispersion Cyprus is, with a share of about 46 per cent, the country where inheritance variation among households is most important. In most countries, differences in household characteristics, that is, age, number of adults and children, marital status and education level, account for more than half (up to 77 per cent in the case of Portugal) of wealth inequality. However, in the case of education we have to take into account that the literature points to a strong correlation between attainment levels acquired by ancestors and their offspring, thus part of the inequality is the outcome of an inter vivos transfer in kind. The result of the analysis is that only a part of wealth inequality can be explained by the life cycle hypothesis (which argues that a major source of wealth inequality is to be found in age variations between households), differences in the abilities of households to accrue and accumulate out of income, and further variations in household characteristics. Whether or not a person is born into a wealthy and educated family and thus inherits assets determines to a considerable extent whether he or she will make a fortune. The research presented emphasizes this obvious fact. The effect is strongest in Austria, Germany and Cyprus.

\section{REFERENCES}

Arrondel, L., Laferrere, A. (2001): Taxation and wealth transmission in France, in: Journal of Public Economics, 79, 3-33.

Azpitarte, F. (2010): The household wealth distribution in Spain: the role of housing and financial wealth, in: Hacienda Pública Española, 194(3), 65-90.

Bonesmo Fredriksen, K. (2012): Less income inequality and more growth - are they compatible? Part 6: the distribution of wealth, OECD Economics Department Working Papers, No 929, OECD Publishing.

Bourguignon, F. (1979): Decomposable income inequality measures, in: Econometrica, 48, 901-920.

Brandolini, A., Cannari, L., D’Alessio, G., Faiella, I. (2004): Household wealth distribution in Italy in the 1990s, Levy Economics Institute Working Paper, No 414.

Burbidge, J.B., Magee, L., Robb, A.L. (1988): Alternative transformations to handle extreme values of the dependent variable, in: Journal of the American Statistical Association, 83(401), $123-127$.

Chantreuil, F., Trannoy, A. (2013): Inequality decomposition values: the trade-off between marginality and efficiency, in: Journal of Economic Inequality, 11(1), 83-98. 
Chernozhukov, V., Fernandez-Val, I., Melly, B. (2009): Inference on counterfactual distributions, CeMMAP - Centre for Microdata Methods and Practice, Institute for Fiscal Studies, Working Papers CWP09/09.

Cowell, F.A. (1980): On the structure of additive inequality measures, in: Review of Economic Studies, 47, 521-531.

Cowell, F.A., Fiorio, C.V. (2009): Inequality decompositions: a reconciliation, ECINEQ Working Paper Series WP 2009-117.

Davies, J.B., Shorrocks, A.F. (2000): The distribution of wealth, in: Atkinson, A.B., Bourguignon, F. (eds), Handbook of Income Distribution, vol. 1, Amsterdam: Elsevier, 605-675.

Davies, J.B., St-Hilaire, F. (1987): Reforming Capital Income Taxation in Canada: Efficiency and Distributional Effects of Alternative Options, Ottawa: Economic Council of Canada.

European Central Bank (2013): The Eurosystem Household Finance and Consumption Survey methodological report for the first wave, Statistics Paper Series, No 1.

Fei, J.C.H., Rania, G., Kuo, S.W.Y. (1978): Growth and the family distribution of income by factor components, in: Quarterly Journal of Economics, 92, 17-53.

Fessler, P., Schürz, M. (2013): Cross-country comparability of the Eurosystem Household Finance and Consumption Survey, in: OeNB Monetary Policy \& the Economy, Q2(13), 29-50.

Fessler, P., Lindner, P., Segalla, E. (2014): Net wealth aross the euro area: why household structure matters and how to control for it, ECB Working paper series, No 1663.

Fessler, P., Mooslechner, P., Schürz, M. (2008a): Reich bleiben in Österreich, in: Wirtschaft und Gesellschaft, 39, Jahrgang (2013), Heft 3, Vienna.

Fessler, P., Mooslechner, P., Schürz, M. (2008b): How inheritances relate to wealth distribution? Theoretical reasoning and empirical evidence on the basis of LWS data, Luxembourg Wealth Study Working Paper No 6.

Fields, G.S. (1979): Income inequality in urban Colombia: a decomposition analysis, in: Review of Income and Wealth, 25, 327-341.

Fields, G.S. (2003): Accounting for income inequality and its change: a new method, with application to the distribution of earnings in the United States, in: Research in Labor Economics, 22, 1-38.

Fields, G.S., Yoo, G. (2000): Falling labor income inequality in Korea's economic growth: patterns and underlying causes, in: Review of Income and Wealth, 46(2), 139-159.

Fortin, N., Lemieux, T., Firpo, S. (2010): Decomposition methods in economics, National Bureau of Economic Research, Working Paper 16045.

Foster, J.E., Shneyerov, A.A. (1996a): Path independent inequality measures, Department of Economics, Vanderbilt University Discussion Paper No 97-W04.

Foster, J.E., Shneyerov, A.A. (1996b): A general class of additively decomposable inequality indices, Department of Economics, Vanderbilt University Discussion Paper No 97-W10.

Gale, W.G., Scholz, J.K. (1994): Intergenerational transfers and the accumulation of wealth, in: Journal of Economic Perspectives, 8(4), 145-160.

Gunatilaka, R., Chotikapanich, D. (2009): Accounting for Sri Lanka’s expenditure inequality 19802002: regression-based decomposition approaches, in: Review of Income and Wealth, 55(4), 882-906.

Hauser, R., Stein, H. (2003): Inequality of the distribution of personal wealth in Germany 1973-1998, Levy Economics Institute Working Paper, No 398.

Heshmati, A. (2004): A review of decomposition of income inequality, IZA Discussion Paper Series, No 1221 , Bonn.

Israeli, O. (2007): A Shapley-based decomposition of the R-square of a linear regression, in: Journal of Economic Inequality, 5, 199-212.

Jäntti, M. (2006): Trends in the distribution of income and wealth: Finland 1987-1998, in: Wolff, E.N. (ed.), International Perspectives on Household Wealth, Cheltenham, UK and Northampton, MA: Edward Elgar, 295-329.

Jäntti, M., Sierminska, E. (2007): Survey estimates of wealth holdings in OECD countries: evidence on the level and distribution across selected countries, UNU Wider, Research Paper No 2007/17.

Kennickell, A. (2003): A rolling tide: changes in the distribution of wealth in the US, 1989-2001, paper presented at the Levy Institute Conference on International Perspectives on Household Wealth, October. 
Kessler, D., Masson, A. (1989): Bequest and wealth accumulation: are some pieces of the puzzle missing?, in: Journal of Economic Perspectives, 3(3), 141-152.

Klevmarken, A.N. (2004): On the wealth dynamics of Swedish families, 1984-98, in: Review of Income and Wealth, 50(4), 469-607.

Kotlikoff, L.J., Summers, L.H. (1981): The role of intergenerational transfers in aggregate capital accumulation, in: Journal of Political Economy, 89, 372-391.

Kotlikoff, L.J., Summers, L.H. (1988): The contribution of intergenerational transfers to total wealth: a reply, in: Kessler, D., Masson, A. (eds), Modelling the Accumulation and Distribution of Wealth, Oxford: Clarendon Press, 53-67.

Leitner, S., Stehrer, R. (2014): Drivers of inequality and poverty in the CEE and other EU member states: a Shapley value decomposition analysis, wiiw Research Report 398, The Vienna Institute for International Economic Studies (wiiw), Vienna.

Lindner, P. (2011): Decomposition of wealth and income using micro data from Austria, OeNB Working Papers 173, Oesterreichische Nationalbank (OeNB), Vienna.

Lindner, P. (2015): Factor decomposition of the wealth distribution in the euro area, in: Empirica, 42(2), 291-322.

MacKinnon, J.G., Magee, L. (1990): Transforming the dependent variable in regression models, in: International Economic Review, 31(2), 315-339.

Manna, R., Regoli, A. (2012): Regression-based approaches for the decomposition of income inequality in Italy, 1998-2008, Rivista di Statistica ufficiale, N. 1/2012, Istituto nazionale di statistica, Rome.

Modigliani, F. (1988): The role of intergenerational transfers and life cycle saving in the accumulation of wealth, in: Journal of Economic Perspectives, 2, 15-40.

Molini, V., Wan, G. (2008): Discovering sources of inequality in transition economies: a case study of rural Vietnam, in: Journal of Economic Change, 41, 75-96.

Morduch, J., Sicular, T. (2002): Rethinking inequality decomposition, with evidence from rural China, in: Economic Journal, 112, 93-106.

Morissette, R., Zhang, X., Drolet, M. (2003): The evolution of wealth inequality in Canada, 19841999, Levy Economics Institute Working Paper, No 369.

OECD (2011): Divided We Stand: Why Inequality Keeps Rising, Paris: OECD Publishing.

Pence, K.M. (2006): The role of wealth transformations: an application to estimating the effect of tax incentives on saving, in: The B.E. Journal of Economic Analysis \& Policy, 5(1), 1-26.

Piketty, T. (2014): Capital in the Twenty-First Century, Cambridge, MA: Harvard University Press.

Piketty, T., Zucman, G. (2014): Wealth and inheritance in the long run, Centre for Economic Policy Research, Discussion Paper No 10072.

Schneebaum, A., Rehm, M., Mader, K., Klopf, P., Hollan, K. (2014): The gender wealth gap in Europe, Department of Economics, Vienna University of Economics and Business (WU), Working Paper No 186.

Shorrocks, A.F. (1980): The class of additively decomposable inequality measures, in: Econometrica, 48(3), 613-625.

Shorrocks, A.F. (1982): Inequality decomposition by factor components, in: Econometrica, 50(1), $193-212$.

Shorrocks, A.F. (1984): Inequality decomposition by population subgroups, in: Econometrica, 52(1), $1369-1385$.

Shorrocks, A.F. (1999): Decomposition procedures for distributional analysis: a unified framework based on the Shapley value, Draft paper, University of Essex.

Shorrocks, A.F. (2013): Decomposition procedures for distributional analysis: a unified framework based on the Shapley value, in: Journal of Economic Inequality, 11(1), 99-126.

Sierminska, E., Doorly, K. (2012): Decomposing household wealth portfolios across countries: an age-old question?, CEPS/INSTEAD Working Paper No 2012-32, Luxembourg.

Sierminska, E., Frick, J., Grabka, M. (2010): Examining the gender wealth gap, in: Oxford Economic Papers, 62(4), 669-690.

Theil, H. (1972): Statistical Decomposition Analysis with Applications in the Social and Administrative Sciences, Amsterdam: North-Holland. 
Tiefensee, A., Grabka, M.M. (2014): Comparing wealth: data quality of the HFCS, DIW Discussion Papers 1427, German Institute for Economic Research (DIW), Berlin.

United Nations Economic Commission for Europe (2011): Canberra Group Handbook on Household Income Statistics, Geneva: United Nations.

Wan, G. (2002): Regression-based inequality decomposition: pitfalls and a solution procedure, UNU-WIDER, Discussion Paper No 2002/101.

Wan, G. (2004): Accounting for income inequality in rural China: a regression-based approach, in: Journal of Comparative Economics, 32, 348-363.

Wolff, E.N. (2002): Inheritances and wealth inequality, 1989-1998, in: American Economic Review, 92(2), 260-264.

Wolff, E. (2007): Recent trends in household wealth in the United States: rising debt and the middleclass squeeze, Levy Economics Institute Working Paper, No 502.

Wolff, E. (2010): Recent trends in household wealth in the United States: rising debt and the middleclass squeeze - an update to 2007, Levy Economics Institute Working Paper, No 589.

Wolff, E.N., Gittleman, M. (2011): Inheritances and the distribution of wealth or whatever happened to the great inheritance boom?, ECB Working Paper No 1300. 